\title{
PREBIOTIC ACTIVITY OF FRUCTOOLIGOSACCHARIDES PRODUCED BY BACILLUS SUBTILIS NATTO CCT 7712
}

\author{
P.B. Silva ${ }^{a}$, S. GARCIA ${ }^{b}$, C. BALDo ${ }^{a *}$ and M.A.P.C. Celligol ${ }^{a}$ \\ aDepartment of Biochemistry and Biotechnology, State University of Londrina, Rodovia Celso Garcia Cid, PR 445 \\ Km 380, Londrina, Paraná State. Brazil. \\ ${ }^{b}$ Department of Food Science and Technology, State University of Londrina, Rodovia Celso Garcia Cid, PR 445 \\ Km 380, Londrina, Paraná State. Brazil.
}

(Received: 25 March 2015; accepted: 18 August 2015)

Bacillus subtilis natto is a potential source of fructooligosaccharides (FOS), which can be obtained by fermentation and may stimulate the growth of beneficial microorganisms in the colon representing a strategy to manipulate the intestinal microbiota acting as a prebiotic compound. The present study focuses on the ability of Lactobacillus ssp. strains to utilize FOS as a sole energy source. The results showed that FOS was equally good as glucose to provide energy source. The highest prebiotic activity score was obtained with Lactobacillus plantarum ATCC 14917 grown on FOS (0.526), followed by Lactobacillus casei (LC-1) (0.222). The lowest score was for Lactobacillus paracasei ATCC $27092(-0.051)$. The results suggests that specific combinations of probiotic (L. plantarum ATCC 14917 and L. casei (LC-1)) and prebiotic (FOS) could be used as synbiotics in dairy and other foods.

Keywords: fructooligosaccharides, probiotics, prebiotic score, Lactobacillus spp.

Fructooligosaccharides (FOS) are oligosaccharides of fructose containing a single glucose moiety in which fructosyl units are bound at the $\beta(2 \rightarrow 1)$ position of a sucrose molecule (YUN, 1996). They have been self-affirmed by the manufacturers as GRAS (generally recognized as safe) and have been added to infant formulas, yogurt, bakery, and other food products and food supplements (SPeigel et al., 1994; IshWARYa \& PrabHASANKAR, 2013). FOS from microbial origin has attracted particular attention, since the large-scale production is not complicated and their sweet taste is very similar to the sucrose. In 2008, the prebiotic market earned 295.5 million Euros and was estimated to reach 766.9 million Euros by 2015, indicating the extraordinary market growth for the prebiotic foods (MORRIS \& MORRIS, 2012).

Industrially, FOS are mainly produced from sucrose by microbial fructosyltransferases from fungi and bacteria (Yun, 1996; Euzenat et al., 1997; Passos \& Park, 2003; Sangeetha et al., 2005). Bacillus subtilis natto has been cited as a good producer of FOS by expressing the great amounts of enzymes involved on the sucrose metabolism (SHIH et al., 2010; GonÇALVES et al., 2013; SiLVA et al., 2014). Lactic acid bacteria are the well-known ingredients of several traditional fermented foods and dairy products (REDDY et al., 2007). Most of them were isolated from different fermented foods and ecosystems and are known to exhibit certain nutritional and therapeutic benefits. The aim of the present investigation was to verify the Lactobacillus casei (LC-1), Lactobacillus paracasei ATCC 27092, and Lactobacillus plantarum ATCC 14917 ability to metabolize FOS as sole carbon source.

\footnotetext{
* To whom correspondence should be addressed. Phone: +55-43-33715476; e-mail: cristianibaldo@uel.br
} 
Several quantitative approaches were devised to determine the functional activity of prebiotics during in vitro fermentation conditions. The prebiotic activity score was chosen because it is an efficient and simple methodology to study the prebiotic potential of FOS and other carbohydrates. This method was established by HuEBNER and co-workers (2007) and is based on the comparison between growth of the probiotics and gastrointestinal strains, such as Escherichia coli, in a growth medium containing glucose or the prebiotic compound. This test is the basis for the selection of combined effects of probiotics and prebiotics in foods to predicting the extent of the prebiotic activity.

\section{Materials and methods}

\subsection{Microorganisms and fermentation media}

B. subtilis natto CCT 7712 was maintained at $4{ }^{\circ} \mathrm{C}$ on medium containing $\left(\mathrm{g} \mathrm{l}^{-1}\right)$ : peptone 50 , yeast extract 30 and agar 20 . This strain was isolated from fermented soybeans, a Japanese food called "natto" at the Department of Biochemistry and Biotechnology of State University of Londrina (Brazil) and identified by Fundação André Tosello (Campinas-Brazil). L. paracasei ATCC 27092, L. plantarum ATCC 14917, and E. coli ATCC 55302 were kindly donated by Department of Food Science and Technology of State University of Londrina. $L$. casei (LC-1) were donated by Christian Hansen (Valinhos, São Paulo, Brazil). The Lactobacillus strains were maintained on a Man-Rogosa-Sharpe-MRS (MAN et al., 1960) containing $150 \mathrm{~g} \mathrm{l}^{-1}$ of glycerol, and E. coli ATCC 55302 was maintained in the bacteriological agar (Himedia, India). For prebiotic activity assays the Lactobacillus strains were cultivated in MRS medium containing glucose $20 \mathrm{~g} \mathrm{l}^{-1}$. The $E$. coli was cultured in media TSA (Tryptic Soy Agar), TSB (Tryptic Soy Broth) (Himedia, India), and M9 medium (SAmBrook et al., 1989).

\subsection{Inoculum preparation}

The inoculum was prepared from stock culture of B. subtilis natto CCT 7712, which was transferred to $125 \mathrm{ml}$ Erlenmeyers flasks containing $25 \mathrm{ml}$ of medium $\left(\mathrm{g} \mathrm{l}^{-1}\right)$ : sucrose 100; yeast extract 2; $\mathrm{KH}_{2} \mathrm{PO}_{4} 2,\left(\mathrm{NH}_{4}\right)_{2} \mathrm{SO}_{4} 1$, and $\mathrm{MgSO}_{4}\left(7 \mathrm{H}_{2} \mathrm{O}\right)$ 0.5. After incubation (150 r.p.m., $37^{\circ} \mathrm{C}, 48 \mathrm{~h}$ ), the medium was centrifuged at $9056 \mathrm{~g}$ and the cells were resuspended in saline solution $0.9 \%(\mathrm{w} / \mathrm{v})$. The inoculum containing $0.2 \mathrm{~g} \mathrm{l}^{-1}$ of cells was used in all fermentations.

\subsection{FOS production}

The production of FOS was carried out using the optimum conditions determined previously (SiLva et al., 2014). The fermentation medium contained $\left(\mathrm{g} \mathrm{l}^{-1}\right)$ : sucrose 300 , yeast extract 2.0; $\mathrm{KH}_{2} \mathrm{PO}_{4} 1.0,\left(\mathrm{NH}_{4}\right)_{2} \mathrm{SO}_{4} 3.0, \mathrm{MgSO}_{4} .7 \mathrm{H}_{2} \mathrm{O} 0.6, \mathrm{MnSO}_{4} 0.2$. The $\mathrm{pH}$ was set to 7.7 and the flasks were incubated under orbital shaking at 230 r.p.m., for $24 \mathrm{~h}$.

\subsection{Purification of FOS}

The cell free medium was filtered on a membrane with a porosity of $3 \mathrm{kDa}$ and then was subjected to precipitation with three volumes of $90 \%(\mathrm{v} / \mathrm{v})$ of cold ethanol. The precipitate was washed with ethanol and dried at $70{ }^{\circ} \mathrm{C}$. The purity of the material was checked using 
high performance liquid chromatography (HPLC), which showed complete removal of monosaccharides and disaccharides as well as polymers of fructose with molecular weight higher than $3 \mathrm{kDa}$ (SiLva et al., 2014).

\subsection{Prebiotic activity}

The first step was to evaluate the prebiotic activity of purified FOS (HuEBNER et al., 2007). Initially, the strains of L. casei (LC-1), L. paracasei ATCC 27092, and L. plantarum ATCC 14917 were activated by cultivation for $24 \mathrm{~h}$ in MRS medium containing glucose $20 \mathrm{~g} \mathrm{l}^{-1}$. The MRS medium without glucose and MRS containing glucose $20 \mathrm{~g} \mathrm{l}^{-1}$, was used as a negative and positive control, respectively. For the test, $100 \mu \mathrm{l}$ of an overnight culture of each probiotic strain were added to $10 \mathrm{ml}$ of MRS containing purified FOS $20 \mathrm{~g} \mathrm{l}^{-1}$. The samples were maintained at $37^{\circ} \mathrm{C}$ for $48 \mathrm{~h}$. The fermentations were interrupted by centrifugation at $2000 \times$ $g$ for $10 \mathrm{~min}$, at $4{ }^{\circ} \mathrm{C}$, followed by measuring of $\mathrm{pH}$ and analytical determinations. The score of prebiotic activity was calculated according to HUEBNER and co-workers (2007), using the probiotics strains of L. casei (LC-1), L. paracasei ATCC 27092, and L. plantarum ATCC 14917 , and an enteric strain of $E$. coli. Prebiotic activity reflects the ability of a given substrate to support the growth of an organism relative to other organisms and relative to growth on a non-prebiotic substrate, such as glucose. The assay was performed by adding $100 \mu \mathrm{l}$ of an overnight culture of each probiotic strain to separate tubes with MRS containing glucose $20 \mathrm{~g} \mathrm{l}^{-1}$ or FOS $20 \mathrm{~g} \mathrm{l}^{-1}$. The cultures were incubated at $37^{\circ} \mathrm{C}$ for $24 \mathrm{~h}$. For E. coli experiments the M9 medium was used. The viable cells were defined as colony forming units (CFU). The prebiotic activity score was determined using Equation 1.

prebiotic activity score $=\left[\left(\right.\right.$ probiotic $\log C F U m^{-1}$ on a - probiotic $\log C F U m l^{-1}$ on b) $)$ (probiotic $\log C F U \mathrm{ml}^{-1}$ on $\mathrm{c}$ - probiotic $\log C F U \mathrm{ml}^{-1}$ on d)] - [E.coli $\log C F U \mathrm{ml}^{-1}$ on aE.coli $\log C F U m^{-1}$ on b)/(E.coli $\log C F U ~ m l^{-1}$ on c - E.coli $\log C F U l^{-1}$ on d)] (Eq. 1)

where a: FOS 24 h; b: FOS 0 h; c: glucose 24 h, d: glucose 0 h

\subsection{Analytical methods}

The cell growth was determined by turbidimetry at $600 \mathrm{~nm}$ and correlated to the biomass curve in $\mathrm{g}^{-1}$ of each strain used. For the quantification of lactate and acetate, samples of the culture supernatant were filtered through membranes with a pore size $0.45 \mu \mathrm{m}$ (Millipore) and $20 \mu \mathrm{l}$ of filtered sample was injected into a high performance liquid chromatograph (HPLC) (Shimadzu Corporation, Kyoto, Japan) equipped with a $7.8 \times 300 \mathrm{~mm}$ HPX-87H organic acid column Aminex (Bio-Rad, CA, USA) according to BenEdini and SANTANA (2013), with modifications. In the present study, the mobile phase was composed of 0.005 mol ${ }^{-1} \mathrm{H}_{2} \mathrm{SO}_{4}$ solution pumped at a rate of $0.7 \mathrm{ml} \mathrm{min}{ }^{-1}$, instead of $0.004 \mathrm{~mol} \mathrm{l}^{-1} \mathrm{H}_{2} \mathrm{SO}_{4}$ solution and flow rate of $0.6 \mathrm{ml} \mathrm{min}{ }^{-1}$ used by BENEDINI and SANTANA (2013). The column was maintained at $60{ }^{\circ} \mathrm{C}$. The peak elution profile was monitored with a Shimadzu RID-10A refractive index detector (Shimadzu Corporation, Kyoto, Japan). The FOS and glucose consumptions were monitored by HPLC (Shimadzu RID-10A) coupled to a refractive index detector, using an Aminex Carbohydrate HPX-87C (300×7.8 mm, Bio-Rad) column. The mobile phase was Milli-Q water at a flow rate of $0.6 \mathrm{ml} \mathrm{min}$. The column temperature was kept constant at $80{ }^{\circ} \mathrm{C}$. The cell supernatant $(20 \mu \mathrm{l})$ was eluted with $0.6 \mathrm{ml}$ of Milli-Q 
water/min. The concentration of FOS of the supernatant was estimated using a nystose analytical standard $\left(\mathrm{GP}_{3}-666.58 \mathrm{Da}\right)$ and 1-kestose $\left(\mathrm{GF}_{2}-504.44 \mathrm{Da}\right)$ from Sigma-Aldrich. The total FOS production was calculated as the sum of 1-kestose and 1-nystose and expressed in $\mathrm{g}^{-1}$.

\subsection{Statistical analysis}

The variance was analysed by ANOVA method and the media compared by Tukey's test at $5 \%$ probability level $(\mathrm{P}<0.05)$, using the Software Statistica 7.0. All the experiments were performed in triplicate.

\section{Results and discussion}

In this present study, a quantitative score that describes the extent to which prebiotics support selective growth of lactic acid bacteria was used to investigate the prebiotic activity of FOS produced by $B$. subtilis natto CCT 7712. The results showed that all tested strains were able to grow on medium containing FOS as sole energy source, suggesting a possible role of FOS as a prebiotic sugar. The biomass concentrations of $L$. casei (LC-1), L. paracasei ATCC 27092, and L. plantarum ATCC 14917 are shown in Table 1. As expected, the growth was not observed in media without carbohydrate (data not shown). The decrease of fermentative medium $\mathrm{pH}$ is an important indicative that a sugar could be fermented by Lactobacillus strains (Hu et al., 2006). In this sense, a reduction of $\mathrm{pH}$ of culture medium was detected for the three strains studied (Table 1). However, the major reduction was observed with $L$. paracasei ATCC 27092, where the $\mathrm{pH}$ decreases from 6.5 to 4.8 after $48 \mathrm{~h}$ of fermentation. The consumption of FOS was also observed for all tested strain of Lactobacillus, suggesting that they can ferment FOS, a result consistent with that previously reported by KAPLAN and Hutkins (2000). Similar results were also reported by Hernalsteens and MaUgeri (2010) who evaluated the effect of FOS obtained by enzymatic synthesis of a fructosyltransferase from Rhodotorula sp. on the growth of Lactobacillus sp. and Bifidobacterium sp. and concluded that synthesized FOS had a prebiotic effect, promoting the growth of probiotic bacteria. Hu and co-workers (2006) also reported the prebiotic effects of oligosaccharides prepared by enzymatic hydrolysis of agarose on Lactobacillus strains.

Table 1. FOS utilization by lactic acid bacteria

\begin{tabular}{llll}
\hline & $\begin{array}{l}\text { L. casei } \\
\text { LC-1 }\end{array}$ & $\begin{array}{l}\text { L. paracasei } \\
\text { ATCC } 27092\end{array}$ & $\begin{array}{c}\text { L. plantarum } \\
\text { ATCC } 14917\end{array}$ \\
\hline Biomass $\left(\mathrm{g}^{-1}\right)$ & $0.54 \pm 0.11^{\mathrm{a}}$ & $1.45 \pm 0.19^{\mathrm{b}}$ & $0.98 \pm 0.04^{\mathrm{c}}$ \\
Final pH & $5.09 \pm 0.04^{\mathrm{a}}$ & $4.86 \pm 0.005^{\mathrm{b}}$ & $4.94 \pm 0.08^{\mathrm{b}}$ \\
Acetate $(\mathrm{mM})$ & $11.58 \pm 0.59^{\mathrm{a}}$ & $24.48 \pm 8.71^{\mathrm{b}}$ & $36.8 \pm 0.63^{\mathrm{b}}$ \\
Lactate $(\mathrm{mM})$ & $54.74 \pm 7.59^{\mathrm{a}}$ & $58.33 \pm 16.61^{\mathrm{a}}$ & $54.44 \pm 9.26^{\mathrm{a}}$ \\
Final FOS $\left(\mathrm{g} \mathrm{l}^{-1}\right)$ & $15.09 \pm 3.6^{\mathrm{a}}$ & $16.65 \pm 1.04^{\mathrm{a}}$ & $18.7 \pm 1.04^{\mathrm{a}}$ \\
\hline
\end{tabular}

* Different letters in the same line indicate significant differences $(\mathrm{P}<0.05)$ 
Organic acids produced by microorganisms as metabolic end products of prebiotics are also an indicative of the fermentative utilization of prebiotic oligosaccharides. According to the results, the three Lactobacillus strains were able to produce equivalent concentrations of lactate (Table 1). However, the production of acetate was higher for L. paracasei ATCC 27092 and L. plantarum ATCC 14917. Similar results were found by NINGEGOwDA and GuRudutT (2012) that showed that lactic acid was the main metabolic end product, with a concentration of $142 \pm 5 \mathrm{mM}$ after $18 \mathrm{~h}$ of fermentation. The next step was to quantify the prebiotic activity of FOS using the prebiotic activity score. The other characteristic property of a prebiotic substrate is that it should be selective and not fermented by commensal organisms. Therefore, growth on prebiotic was also determined for an enteric bacteria, $E$. coli, chosen to represent the enteric portion of the commensal microbiota. Growth of these enteric bacteria on FOS was significantly smaller compared to the growth on glucose (Table 2). The results also showed that L. casei (LC-1) had a significantly higher growth on medium containing glucose than in the medium containing FOS. On the other hand, $L$. paracasei ATCC 27092 and L. plantarum ATCC 14917 showed the same growth pattern with both carbon sources. Importantly, the number of $\mathrm{CFU} \mathrm{ml}{ }^{-1}$ was greater than $10^{6}$ for the three Lactobacillus strains evaluated. This value constitutes the minimum amount required for application of probiotic bacteria in food (ThUAYTONG \& ANPRUnG, 2011).

Table 2. Microbial population of lactic acid and enteric bacteria grown on medium containing FOS and glucose

\begin{tabular}{lcc}
\hline & \multicolumn{2}{c}{ Cell population $\left[\log _{10}\left(\mathrm{CFU} \mathrm{ml}^{-1}\right)\right]$} \\
\cline { 2 - 3 } & FOS & Glucose \\
\hline L. casei LC-1 & $7.6 \pm 0.00^{\mathrm{a}}$ & $8.79 \pm 0.17^{\mathrm{b}}$ \\
L. paracasei ATCC 27092 & $7.54 \pm 0.00^{\mathrm{a}}$ & $8.99 \pm 0.03^{\mathrm{a}}$ \\
L.plantarum ATCC 14917 & $8.88 \pm 0.10^{\mathrm{a}}$ & $8.57 \pm 0.69^{\mathrm{a}}$ \\
E. coli ATCC 55302 & $8.56 \pm 0.05^{\mathrm{a}}$ & $9.00 \pm 0.03^{\mathrm{b}}$ \\
\hline
\end{tabular}

Values are represented as mean \pm standard deviation. Mean values followed by different letters in the same line are significantly different for $\mathrm{P}<0.05$.

The prebiotic activity scores were calculated from the microbial growth in $24 \mathrm{~h}$, and are showed in Figure 1. The highest score was obtained for L. plantarum ATCC 14917 grown on FOS, and the lowest score was for L. paracasei ATCC 27092. According to HuEBNER and coworkers (2007), a low or negative prebiotic activity score was obtained if the test strain grew less well on the prebiotic compared with that on glucose and/or had less growth on the prebiotic than the growth of the enteric strain on the prebiotic sugar.

In summary, the results found here suggest that FOS could be used in association with the probiotic L. plantarum ATCC 14917 and L. casei (LC-1) to formulate a symbiotic food. 


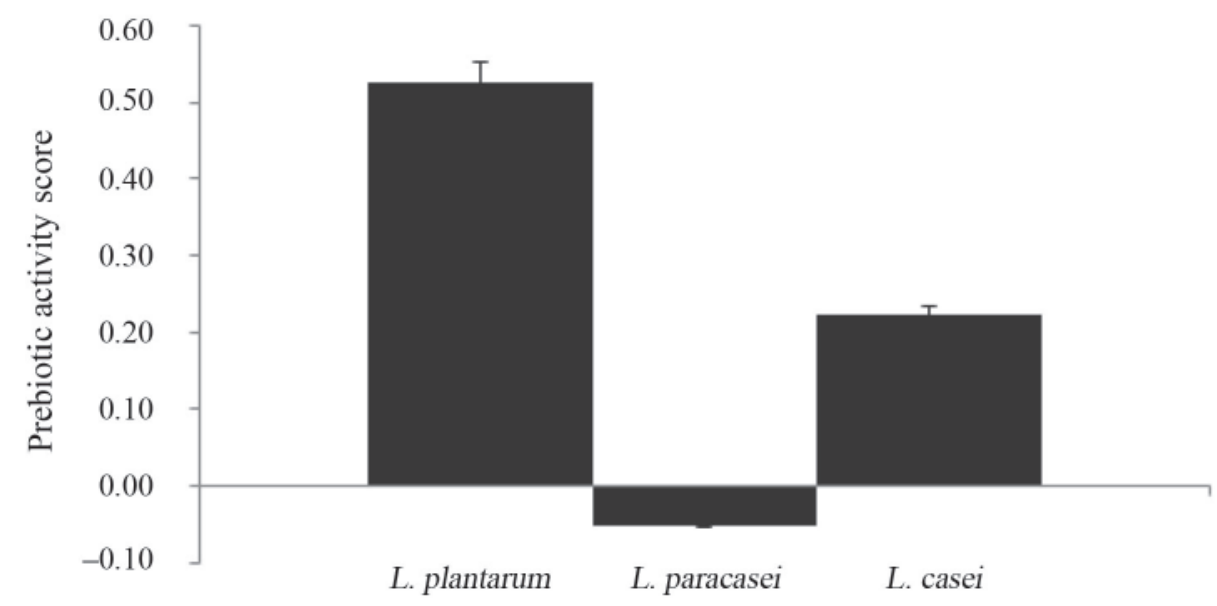

\section{Lactobacillus strains}

Fig. 1. Prebiotic activity scores of Lactobacillus strains grown on FOS produced by B. subtilis natto CCT 7712

\section{Conclusions}

In conclusion, these results suggest that FOS was equally as good as glucose to supporting growth of lactic acid bacteria. The overall promising results were obtained with L. plantarum ATCC 14917 and L. casei (LC-1), indicating that both strains in combination with FOS produced by $B$. subtilis natto CCT 7712 could be a viable probiotic-based functional food approach. In addition, these testing may be useful in identifying combinations of probiotics and prebiotics that could be added into dairy and other foods.

The authors acknowledge the financial support provided by the CAPES/PNPD and the Araucária Foundation Brazil.

\section{References}

Benedini, L.J. \& Santana, M.H.A. (2013): Effects of soy peptone on the inoculum preparation of Streptococcus zooepidemicus for production of hyaluronic acid. Bioresource Technol., 130, 798-800.

Euzenat, O., Guibert, A. \& Combert, D. (1997): Production of the fructo-oligosaccharides by levansucrase from Bacillus subtilis C4. Process Biochem., 32, 237-243.

Gonçalves, B.C.M., Mantovan, J., Ribeiro, M.L.L., Borsato, D. \& Celligoi, M.A.P.C. (2013): Optimization production of thermo active levansucrase from Bacillus subtilis Natto CCT 7712. JABB, 1, 1-8.

Hernalsteens, S. \& Maugeri, F. (2010): Synthesis of fructooligosaccharides using extracellular enzymes from Rhodotorula sp. J. Food Biochem., 34, 520-534.

Hu, B., Gong, Q., WAng, Y., MA, Y., Li, J. \& Yu, W. (2006): Prebiotic effects of neoagaro-oligosaccharides prepared by enzymatic hydrolysis of agarose. Anaerobe, 12, 260-266.

Huebner, J., Wehling, R.L. \& Hutkins, R.W. (2007): Functional activity of commercial prebiotics. Int. Dairy J., 17, $770-775$.

IshWARya, S.P. \& Prabhasankar, P. (2013): Fructooligosaccharide - Retention during baking and its influence on biscuit quality. Food Bioscience, 4, 68-80. 
Kaplan, H. \& Hutkins, R.W. (2000): Fermentation of fructooligosaccharides by lactic acid bacteria and Bifidobacteria. Appl. Environ. Microbiol., 66, 2682-2684.

Man, J.C., Rogosa, A.M. \& Sharpe, M.E. (1960): A medium for the cultivation of Lactobacilli. J. Appl. Bacteriol., $23,130-135$.

Morris, C. \& Morris, G.A. (2012): The effect of inulin and fructo-oligosaccharide supplementation on the textural, rheological and sensory properties of bread and their role in weight management: A review. Food Chem., 133, 237-248.

NingeGOWDA, M.A. \& GURUDUTT, P.S. (2012): In vitro fermentation of prebiotics by Lactobacillus plantarum CFR 2194: selectivity, viability and effect of metabolites on $\beta$-glucuronidase activity. World J. Microb. Biot., 28, 901-908.

PASSOS, L.M.L. \& PARK, Y.K. (2003): Frutooligossacarídeos: Implicações na saúde humana e utilização em alimentos. (Fructooligosaccharides: Implications on human health and use in food). Ciência Rural, 33, 385-390.

Reddy, K.B.P.K, Raghavendra, P., Girish Kumar, B., Misra, M.C. \& Prapulla, S.G. (2007): Screening of probiotic properties of lactic acid fermented product: an in vitro evaluation. J. Gen. Appl. Microbiol., 53, 207-213.

Sambrook, J., Fritsch, E.F. \& Maniatis, T. (1989): Molecular cloning. Cold Spring Harbor, N.Y., Cold Spring Harbor Laboratory. 1626 pages.

Sangeetha, P.T., Ramesh, M.N. \& Prapulla, S.G. (2005): Recent trends in the microbial production, analysis and application of fructooligosaccharides. Trends Food Sci. Tech., 16, 442-457.

SHiн, I.L., Chen, L.D. \& Wu, J.W. (2010): Levan production using Bacillus subtilis natto cells immobilized on alginate. Carbohyd. Polym., 82, 111-117.

Silva, P.B., Borsato, D. \& Celligol, M.A.P.C. (2014): Optimization of high production of fructooligosaccharides by sucrose fermentation of Bacillus subtilis natto CCT7712. Am. J. Food Technol., 9, 144-150.

Speigel, J.E., Rose, R., Karabell, P., Frankos, V.H. \& Schmitt, D.F (1994): Safety and benefits of fructooligosaccharides as food ingredients. Food Technol. 48, 85-89.

ThuAYTong, W. \& ANprung, P. (2011): Bioactive compounds and prebiotic activity in Thailand-grown red and white guava fruit (Psidium guajava L.). Food Sci. Technol. Int., 17, 205-212.

YUn, J. (1996): Fructooligosaccharides - occurrence, preparation, and application. Enzyme Microb. Tech., 19, 107117. 